(Nebenbei sei auch auf den Umstand hingewiesen, daß der Februarfleck an der Stelle des großen magnetischen Störenfrieds vom 31 . Oktober 1903 stand, ohne aber wie dieser die magnetische Ruhe der Erde zu alterieren. Andererseits befand sich der Oktoberfleck in derselben Gegend, auf die ich schon in Nr. $398 \mathrm{I}$ der Astr. Nachr. als auf einen Fleckenherd in 1903 und 1904 aufmerksam gemacht habe).

5) Nach der heliogr. Breite geordnet entfielen auch 1905, wie im vorhergehenden Jahre, mehr Flecke auf die nördliche als auf die südliche Halbkugel und erstreckten sich auf beiden bis zum 30. Grad. Von der Gesamtzahl der Gruppen kamen 126 auf die nördliche und 99 auf die südliche Hälfte, also ein Verhältnis von $5: 4$. Bedeutender war der Unterschied in Rücksicht der Größe; denn hier ergibt sich das Verhältnis 6:4. (In Wirklichkeit wird das Übergewicht der Nordhemisphäre noch größer gewesen sein, da

Frankfurt a. M., I 906 Jan. 20. ich die ihr angehörigen großen Oktoberflecke wegen unvollständiger Beobachtung nur teilweise mit in Rechnung ziehen konnte).

Die Hauptmasse lag wieder, wie im vorhergehenden Jahre, nördlich $z$ wischen $5^{\circ}$ und $15^{\circ}$, südlich zwischen $10^{\circ}$ und $20^{\circ}$ Breite, der Schwerpunkt der Entwicklung war aber beiderseits dem Äquator näher gerückt. Auch war die Äquatorzone von $0^{\circ}$ bis $5^{\circ}$ nördlich viel mehr mit Flecken besetzt, als im Vorjahre; denn während damals in diesem Bereich nur am 21 . Dezember eine kleine Gruppe von zwei vereinzelten Kernen zum Vorschein kam, stellten sich diesmal 5 Gruppen ein, davon 2 sogar mit Höfen, die an $2 \mathrm{r}$ Tagen in der Zeit zwischen dem 24. Juni und I I. Dezember bestanden.

Die zahlenmäßigen Belege für die vorstehenden Angaben werden in der V. J. S. der Astr. Ges. gegeben werden.

Th. Epstein.

\title{
Deux nouvelles variables 31 et 32.1906 Cephei.
}

Sur des plaques prises par M. S. Blajko, Mme. L. Ceraski a trouvé deux nouvelles variables. Celle du I 2 février 1906 est BD. $+84^{\circ} 19$, ses coordonnées d'après Carrington sont :

\section{Var, 31.1906 Cophoi.}

$$
\begin{aligned}
& 1855 I^{\mathrm{h}} 2^{\mathrm{m}} 54^{\mathrm{s}} \cdot 2 \quad+84^{\circ} 2 \mathrm{I}^{\prime} 50^{\prime \prime} 4 \\
& 1900 \quad 188.1+843616.0
\end{aligned}
$$

\begin{tabular}{|c|c|c|c|}
\hline 1896 & Oct. & $\begin{array}{r}2 \\
1 \mathrm{I}\end{array}$ & $\begin{array}{l}\text { I } 0.1 \mathrm{gr} . \\
\mathrm{I} 0.4\end{array}$ \\
\hline 189.7 & Mai & 4 & 10.0 \\
\hline & Sept. & 26 & 10.0 \\
\hline 1898 & Mai & I I & 9.8 \\
\hline & $\star$ & I 3 et 16 & 9.8 \\
\hline 1899 & Avril & 110 & 9.9 \\
\hline & Mai & 2 & 9.9 \\
\hline & $\gg$ & 4 & 9.8 \\
\hline & $\gg$ & 5 & 10.0 \\
\hline & 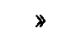 & 7 & 9.8 \\
\hline
\end{tabular}

L'estimation d'éclat sur les photographies donne:

\begin{tabular}{|c|c|c|c|}
\hline \multirow{4}{*}{$\begin{array}{l}1900 \\
1901\end{array}$} & Mai & 5 & $10.0 \mathrm{gr}$ \\
\hline & $»$ & 9 & 9.8 \\
\hline & 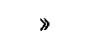 & 12 & 9.8 \\
\hline & 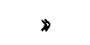 & 17 & 9.8 \\
\hline \multirow[t]{2}{*}{1903} & Avril & 27 & IO. I \\
\hline & $\gg$ & 30 & 9.9 \\
\hline \multirow[t]{4}{*}{1904} & Mai & 8 & 9.5 \\
\hline & » & I 9 & 9.5 \\
\hline & Sept. & 9 & 9.5 \\
\hline & 8 & I 5 & $9 \cdot 3$ \\
\hline 1905 & Déc. & I & 9.8 \\
\hline
\end{tabular}

Autant que ces données permettent de juger, l'eclat photographique varie de 9.3 à $\mathbf{~} 0.5 \mathrm{gr}$., la période est près d'un an. Les observations visuelles de M. S. Blajko en février le portent à dire que la variable est à présent non loin de son maximum.

Moscou, 1906 février 28 .
Voici les coordonnées approchées de la variable trouvée ce 21 février:

$$
\begin{aligned}
& \text { Var. 32.1806 Cephoi. } \\
& \text { I } 855 \quad 0^{\mathrm{h}} 5^{\mathrm{m}} 21^{\mathrm{s}}+73^{\circ} 3: 0 \\
& \text { I900 } \circ 745+73 \text { I8:0 }
\end{aligned}
$$

L'estimation d'éclat sur les photographies fournit à M. S. Blajko les données suivantes:

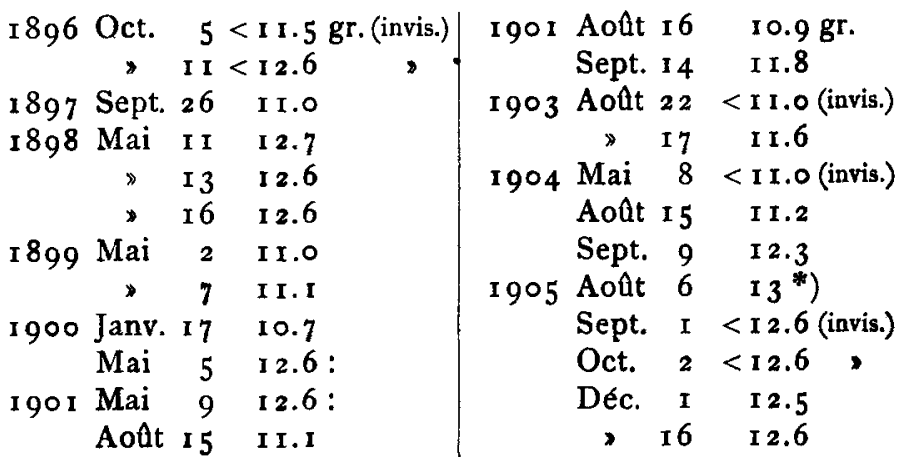

*) à peine perceptible.

Cet examen donne lieu de croir que les grandeurs photographiques varient de 10.8 à 13 et que la période est de 282 jours environ.

Prof. W. Ceraski.

\section{Berichtigung zu Nr. 4070.}

In meinem Artikel über den Schweif des Kometen r905 IV (A. N. 4070, S. 223 ) sind die Koordinaten des Kometen unrichtig angenommen. Es muß sein

$$
\alpha_{\& b}=23^{\mathrm{h}} 47^{\mathrm{m}} 42^{\mathrm{s}} \quad \delta_{\not b}=+54^{\circ} 5^{6} \text {. }
$$

Dadurch werden die anderen Größen in folgender Weise verändert:

Positionswinkel des verlängerten Radiusvektors des Kometen $=103^{\circ} 27^{\prime}$

$$
\begin{array}{llrl}
P=83^{\circ} 14^{\prime} & \varphi=8^{\circ} 18^{\prime} & \eta=0.00153 \\
S=4537 & \xi=0.0105^{2} & 1-\mu=0.7
\end{array}
$$

was übrigens den Schluß, daß der Schweif dem II. Bredichinschen Typus anzugehören scheint, nicht ändert.

Dorpat, I 906 Februar.

K. Pokrowski. 